\title{
Adipose tissue plasticity: how fat depots respond differently to pathophysiological cues
}

\author{
Vanessa Pellegrinelli $^{1}$ - Stefania Carobbio ${ }^{1,2}$ - Antonio Vidal-Puig ${ }^{1,2}$
}

Received: 20 November 2015 / Accepted: 23 February 2016/Published online: 4 April 2016

(C) The Author(s) 2016. This article is published with open access at Springerlink.com

\begin{abstract}
White adipose tissue (WAT) has key metabolic and endocrine functions and plays a role in regulating energy homeostasis and insulin sensitivity. WAT is characterised by its capacity to adapt and expand in response to surplus energy through processes of adipocyte hypertrophy and/or recruitment and proliferation of precursor cells in combination with vascular and extracellular matrix remodelling. However, in the context of sustained obesity, WAT undergoes fibro-inflammation, which compromises its functionality, contributing to increased risk of type 2 diabetes and cardiovascular diseases. Conversely, brown adipose tissue (BAT) and browning of WAT represent potential therapeutic approaches, since dysfunctional white adipocyte-induced lipid overspill can be halted by BAT/browning-mediated oxidative anti-lipotoxic effects. Better understanding of the cellular and molecular pathophysiological mechanisms regulating adipocyte size, number and depot-dependent expansion has become a focus of interest over recent decades. Here, we summarise the mechanisms contributing to adipose tissue (AT) plasticity and function including characteristics and cellular complexity of the various adipose depots and we discuss recent insights into AT origins, identification of adipose precursors, pathophysiological
\end{abstract}

Vanessa Pellegrinelli

vp332@medschl.cam.ac.uk

$\triangle$ Antonio Vidal-Puig

ajv22@medschl.cam.ac.uk

1 University of Cambridge Metabolic Research Laboratories, Level 4, Wellcome Trust-MRC Institute of Metabolic Science, Box 289, Addenbrooke's Hospital, Cambridge CB2 OQQ, UK

2 Wellcome Trust Sanger Institute, Wellcome Trust Genome Campus, Hinxton, Cambridge, UK regulation of adipogenesis and its relation to WAT/BAT expandability in obesity and its associated comorbidities.

Keywords Adipogenesis - Adipose tissue - Development . Fibrosis · Inflammation · Obesity $\cdot$ Plasticity $\cdot$ Review $\cdot$ Tissue remodelling · Type 2 diabetes

\begin{tabular}{ll} 
Abbreviations \\
AP & Adipocyte progenitor \\
AT & Adipose tissue \\
BAT & Brown adipose tissue \\
BMP & Bone morphogenetic protein \\
CD & Cluster of differentiation \\
Cdh5 & Cadherin-5 \\
C/EBP & CCAAT/enhancer-binding protein \\
EC & Endothelial cell \\
ECM & Extracellular matrix \\
FABP4 & Fatty acid binding protein 4 \\
FGF-2 & Fibroblast growth factor 2 \\
FOXC2 & Forkhead box C2 \\
GFP & Green fluorescent protein \\
HFD & High-fat diet \\
MAP4K4 & Mitogen-activated protein 4 kinase 4 \\
MMP & Metalloproteases \\
MSC & Mesenchymal stem cell \\
MYF5 & Myogenic factor 5 \\
NC & Neural crest \\
PAX3/7 & Paired Box $3 / 7$ \\
PDGF & Platelet-derived growth factor \\
PDGFR $\alpha / \beta$ & Platelet-derived growth factor receptor $\alpha / \beta$ \\
PI3K & Phosphoinositide 3-kinase \\
PPAR $\gamma$ & Peroxisome proliferator-activated receptor $\gamma$ \\
SAT & Subcutaneous adipose tissue \\
SREBP1 & Sterol regulatory element binding protein 1 \\
& \\
\hline
\end{tabular}




$\begin{array}{ll}\text { SVF } & \text { Stromal vascular fraction } \\ \text { TZD } & \text { Thiazolidinedione } \\ \text { UCP-1 } & \text { Uncoupling protein-1 } \\ \text { VAT } & \text { Visceral adipose tissue } \\ \text { VEGF } & \text { Vascular endothelial growth factor } \\ \text { WAT } & \text { White adipose tissue } \\ \text { Wt1 } & \text { Wilms' tumour 1 } \\ \text { ZFP423 } & \text { Zinc finger protein } 423\end{array}$

\section{Introduction}

Obesity and its metabolic complications (e.g. type 2 diabetes, cardiometabolic disorders) contributing to the metabolic syndrome represent one of the most important public health problems, with societal and economic implications urging for new therapeutic strategies and effective social policies. White adipose tissue (WAT) plays a key homeostatic role, not only by ensuring efficient energy storage but also by its quick mobilisation (lipids) to ensure peripheral demands. WAT is highly vascularised and innervated as would be expected from a sophisticated constituent of a hormonal homeostatic system [1]. To be able to accommodate the excess energy during the course of obesity, WAT undergoes various cellular and structural remodelling processes: (1) tissue expansion through coordination of increased adipocyte size (hypertrophy) and/or number (hyperplasia) [2]; (2) recruitment of inflammatory cells [3] and (3) remodelling of the vasculature and the extracellular matrix (ECM) to allow adequate tissue expansion, oxygenation and mobilisation of nutrients $[4,5]$. However, when obesity and inflammation are sustained, these adaptive homeostatic mechanisms fail, leading to WAT dysfunction characterised by impaired secretion of adipokines, abnormal lipid storage and adipogenesis, exacerbated fibrosis deposition and insulin resistance.

WAT is organised in discrete anatomical depots identified as subcutaneous adipose tissue (SAT) and visceral adipose tissue (VAT); the expansion of SAT and VAT contributes to obesity and related complications [6]. The 'adipose tissue expandability model' identifies the limited capacity and dysfunctionality of WAT, preventing its expansion and accommodation of surplus of energy, as key determinants for the onset and progression of obesity-associated metabolopathologies as a result of ectopic deposition of toxic lipid species in metabolic organs (i.e. muscle or liver [also known as lipotoxic insult]) [7]. Appropriate WAT plasticity and expandability seem to guard against metabolic disorders [7]. Moreover, promotion of SAT expansion to act as a buffer of lipids is a strategy that may limit the deleterious metabolic effects of VAT [8]. Following a similar concept, transplantation of SAT or removal of VAT in obese mice reversed adverse metabolic effects of obesity and improved glucose homeostasis $[9,10]$.
There is also evidence that the deleterious effects mediated by dysfunctional white adipocyte-induced lipid overspill can be halted by the pro-oxidative anti-lipotoxic effects mediated by brown adipose tissue (BAT) activation. The sympathetic nervous system regulates this function through $\beta$-adrenergic stimulation of brown mature adipocytes' dissipation of energy in the form of heat mediated by mitochondrial uncoupling protein-1 (UCP-1) activation. UCP-1-expressing multilocular adipocytes, termed 'beige' or 'brite' (brown-in-white) adipocytes, can also be found interspersed among white adipocytes within SAT under conditions requiring increased heat production (e.g. chronic cold exposure). Increasing BAT/beige mass has been suggested as a potential therapeutic approach to treat human obesity/diabetes supported by recent studies reporting that, like rodents, humans display highly metabolically active BAT [11-13]. BAT atrophy is observed in obese individuals in association with increased visceral fat, ageing and hyperglycaemia [11], suggesting that defective BAT may exacerbate the development of obesity/complications. However, it cannot be discarded that fat-mediated thermo-insulation may have contributed to BAT regression in these patients.

Departing from the previous evidence, two therapeutic strategies have been tested: (1) improving adipose tissue (AT) plasticity either by expanding anabolic functions of white adipocytes and/or (2) increasing tissue thermogenesis through activation of pre-existing brown adipocytes and/or recruitment and differentiation of brown pre-adipocyte precursors [14]. The success of these strategies may be limited by the uncertainty regarding the identity and origins of adipocytes from different depots and the limited information available about how obesity-associated changes in cellularity/fibroinflammation influence WAT plasticity. Thus a better understanding of the molecular mechanisms and cellular mediators that control AT plasticity and expansion is essential.

In this review, we discuss the current understanding of the origins of WAT, the identity of white/brown/brite adipocyte progenitors (APs) and how depot-specific vascularisation and fibro-inflammation interact with adipogenesis/cell hypertrophy, including the recent insights highlighted by lineagetracing studies in mice and genetic/genomics data obtained from humans. We will notably highlight the structural/ cellular differences in humans compared with rodent models. Finally we discuss BAT plasticity and how obesity-associated environmental cues can be targeted to improve tissue activation and global metabolic homeostasis.

\section{Structural features involved in remodelling of the AT depots}

In addition to the metabolic/functional differences reported in numerous studies [1,15-17], the SAT, VAT and BAT depots also exhibit differences at cellular and structural levels that 
may have an impact on tissue plasticity and remodelling (Table 1). For instance, lean individuals display larger adipocytes in SAT than in VAT whereas mouse studies have shown the presence of smaller adipocytes in SAT than in retroperitoneal VAT [1]. While this discrepancy between the two species has yet to be elucidated, cellular heterogeneity in terms of adipocyte size is also present among human SAT depots depending on body distribution and functional and structural characteristics (more specifically the ECM properties) [18].
In the context of obesity the fibrous ECM may become a limiting factor for adipocyte size (discussed later in the review). BAT differs from other fat pads at the morphological/ molecular level (i.e. vascularisation, innervation) and also by virtue of its unique thermogenic capacity [14] (Table 1). This depot is the dominant site of non-shivering thermogenesis in rodents and is also highly present in infants, maintaining body temperature and warming the blood flow of key organs. Of note, BAT depots persist in human adults, preferentially

Table 1 Structural and cellular variables involved in AT remodelling: comparison between VAT, SAT and BAT

\begin{tabular}{|c|c|c|}
\hline Variable & SAT vs VAT & BAT vs WAT \\
\hline \multicolumn{3}{|l|}{ Adipogenic potential } \\
\hline Adipogenic genes & $\begin{array}{l}\text { Higher expression of Cepbá, Ppary (Pparg), } \\
\text { Dkk2, Stat5 (Stat5a), Bmp2, Bmp4 [71] }]^{\mathrm{a}, \mathrm{d}}\end{array}$ & Lower differentiation potential $[106]^{\mathrm{a}, \mathrm{d}}$ \\
\hline Anti-adipogenic genes & Lower expression of Gata2, $\operatorname{Tg} f b 2$ and Ppar $[71]^{\mathrm{a}, \mathrm{d}}$ & $\begin{array}{l}\text { Higher Pparg2 mRNA expression } \\
\text { (lean/obese) [107-109], }\end{array}$ \\
\hline MSC markers & $\begin{array}{l}\text { Lower expression of } \operatorname{Lif}, \operatorname{Ig} f 1, \operatorname{Ig} f b p 7, \operatorname{Ctg} f, M g p \text {, } \\
\quad \operatorname{Trib2}, \operatorname{Pgn} 1 / \operatorname{Bgn}[71]^{\mathrm{a}, \mathrm{d}}\end{array}$ & $\begin{array}{l}\text { Lower plasticity, mesenchymal stem } \\
\text { cells }[106]^{\text {a,d }}\end{array}$ \\
\hline \multicolumn{3}{|l|}{ Vascularisation } \\
\hline Total vascular density & Lower compared with oVAT (obese) $[110]^{\mathrm{b}, \mathrm{c}}$ & Higher [111] \\
\hline Capillary density & Higher than oVAT of (obese) $[112]^{b, c}$ & $\begin{array}{l}\text { Greater }[111]^{\mathrm{a}, \mathrm{c}}, 3 \text { capillaries per adipocytes } \\
\text { in BAT compared with } 1 \text { per adipocytes } \\
\text { in WAT }[113]^{\mathrm{a}, \mathrm{c}}\end{array}$ \\
\hline Vascular sprouting & Greater $[112]^{\mathrm{b}, \mathrm{c}}$ & NA \\
\hline \multicolumn{3}{|l|}{ Innervation } \\
\hline Neurogenic factors & $\begin{array}{l}\text { Lower mRNA expression of Nnat and Nrg4 } \\
\text { than gVAT [114] }]^{\text {,c }}\end{array}$ & $\begin{array}{l}\text { Lower mRNA expression of Nnat than } \\
\text { gVAT but not Nrg4 }[114]^{\text {a,c }}\end{array}$ \\
\hline Nervous network & NA & $\begin{array}{l}\text { Greater number of noradrenergic } \\
\text { parenchymal nerve fibres }[115]^{\mathrm{a}, \mathrm{c}}\end{array}$ \\
\hline \multicolumn{3}{|l|}{ Cellularity } \\
\hline Immune cells & $\begin{array}{l}\text { Higher CD68 }{ }^{+} \text {cells (obese adolescent) [109], but } \\
\text { lower compared with m/oVAT of lean [116] } \\
\text { and obese [117] individuals }\end{array}$ & $\begin{array}{l}\text { Lower haematopoietic population }\left(\mathrm{CD} 45^{+}\right) \\
{[106]^{\mathrm{a}, \mathrm{c}}}\end{array}$ \\
\hline SVF (except APs) & Higher $[71]^{\mathrm{a}, \mathrm{d}}$ & $\begin{array}{l}\text { Lower F4/80-, CD68- and CD11b }{ }^{+} \text {cells } \\
\text { compared with iSAT/eVAT (lean/obese) } \\
{[92,118]^{\mathrm{a}, \mathrm{c}}}\end{array}$ \\
\hline Adipocyte death/CLS & Lower $[78,117]^{a, b, c}$ & NA \\
\hline \multicolumn{3}{|l|}{ ECM } \\
\hline Tissue expression & $\begin{array}{l}\text { Greater protein expression of type } 1 \text { collagen but } \\
\text { lower level of laminin (b/c) and fibronectin } \\
\text { (lean) }[69]^{\mathrm{a}, \mathrm{c}} \\
\text { Higher COL6A3 mRNA expression (lean/obese) } \\
{[119]^{\mathrm{b}, \mathrm{c}}}\end{array}$ & NA \\
\hline Secretion & $\begin{array}{l}\text { Higher secretion of THSB } 1 / 2 \text {, type } 1 \text { collagen, } \\
\text { SPARC, TIMP1. Lower secretion of laminin, } \\
\text { type } 6 \text { collagen and TGF } \beta 1[120]^{\mathrm{b}, \mathrm{c}}\end{array}$ & NA \\
\hline
\end{tabular}

Comparative studies below were performed in WAT/BAT tissues from lean and/or obese rodents and humans or isolated SVF cells from various depots: SAT (inguinal, iSAT in rodents) and VAT (gonadal [gVAT], epididymal [eVAT] in rodents; omental [oVAT] in humans)

${ }^{\text {a }}$ Rodents

${ }^{\mathrm{b}}$ Humans

${ }^{\mathrm{c}}$ WAT/BAT tissues

${ }^{\mathrm{d}}$ Isolated SVF cells

CLS, crown-like structure; NA, not available; SPARC, secreted protein acidic and cysteine rich; THSB1/2 thrombospondin-1/-2; TIMP1, tissue inhibitor of metalloproteinase 1 
located in cervical, supraclavicular, mediastinal, paravertebral, suprarenal and peri-renal areas [14]. Recent reports have highlighted structural differences between rodents and humans, where BAT deposits are described as being composed of adipocytes displaying a phenotype more similar to rodent beige/brite cells than to canonical brown fat [19].

\section{AT progenitors and development}

In humans, WAT forms during the second trimester of pregnancy [20] and develops (like in other species) in an anterior to posterior, rostral to caudal and dorsal to ventral direction [21]. The recently developed 'AdipoChaser' mouse model [2] precisely elucidated the SAT/VAT developmental timing in mice enabling temporally controlled detection of mature adipocytes and identification of newly formed adipocytes. This model revealed that SAT adipocyte commitment and differentiation occurs early during embryogenesis, in E14-E18, in both sexes and that the number of adipocytes remains very stable postnatally. In contrast, epididymal adipocytes preferentially differentiate postnatally. This process occurs gradually over a relatively long period of time, after birth recruitment of brown-likeadipocytes in SAT has occurred at approximately P10, at room temperature, and disappears spontaneously at around P30. Interestingly, these cells can re-emerge in response to cold or to treatment with a $\beta_{3}$-adrenergic agonist [22].

With respect to BAT development, lineage-tracing studies using Engrailed-1 (En1)-CreERT-inducible mice crossed with Rosa-floxed Stop-LacZ mouse, revealed that E14.5 is the stage at which BAT becomes visible in mouse embryos [23]. However, the divergence between myoblast and BAT precursors already occurs between stage E9.5 and 11.5 in mice [24]. In humans, BAT is detectable at birth, in early childhood and also in adult individuals [11, 12], but the exact embryonic stage at which it makes its first appearance is still unknown.

Embryonic origins of adipocytes Lineage-tracing studies have shown that brown adipocytes and myocytes share common myogenic factor $5(\mathrm{MYF5})^{+}$, paired box $3(\mathrm{PAX} 3)^{+}$and paired box $7(\mathrm{PAX} 7)^{+}$progenitors that originate in the paraxial mesoderm $[14,25]$. Given the absence of this myogenic signature in white adipocytes and their progenitors, it was concluded that white adipocytes would originate preferentially from MYF5 ${ }^{-}$precursors. This assertion was recently challenged by a study in which the conditional deletion of Pten driven by Myf5-Cre caused an overgrowth of BAT and also a paradoxical overgrowth of specific WAT pads and the loss of others [26]. Subsequent lineage-tracing studies have confirmed the presence of some $\mathrm{MYF}^{+}$and $\mathrm{PAX}^{+}$adipocyte progenitors in WAT, indicating that white APs can derive from both $\mathrm{MYF}^{+} / \mathrm{PAX}^{+}$and $\mathrm{MYF}^{-} / \mathrm{PAX}^{+}$. Following on from these studies, the adipocyte origin from $\mathrm{MYF}^{-} / \mathrm{PAX}^{-}$lineages is still not clear.

In addition to a mesodermal origin for adipocytes, the neural crest (NC) also seems to give rise to a subset of adipocytes localised in the salivary gland and ears. An in vivo lineagetracing approach using a Sox10-Cre/Rosa26-YFP model, where NC-derived cells are constitutively labelled, has provided evidence for the contribution of the NC to the adipocyte lineage during normal development [27]. Similarly, another cell fate mapping strategy in mice showed that the earliest wave of mesenchymal stem cells (MSCs) in the embryo is generated from sex-determining region Y-Box $1(\mathrm{SOX} 1)^{+}$ neuroepithelium, in part through a NC intermediate stage [28].

Adipocyte progenitors in adult AT Determination of cell surface markers of APs has been a priority in most studies attempting to elucidate the developmental origin of the adipocyte lineage and identify distinct cellular intermediates between MSCs and mature adipocytes. FACS technology has been used extensively to isolate cell subpopulations from WAT stromal vascular fraction (SVF) based on various cell surface markers, which were then tested for their adipogenic potential in vitro and in vivo after transplantation in lipoatrophic A-Zip mice [29]. Following this strategy, APs were identified as $\mathrm{Lin}^{-} / \mathrm{CD} 34^{+} / \mathrm{CD} 29^{+} / \mathrm{Sca}-1^{+} / \mathrm{CD} 24^{+}$cells able to form white fat when subcutaneously transplanted.

Recent investigations of the close temporal-spatial association between angiogenesis and adipogenesis suggested that the adipose niche is located adjacent to the growing vasculature and that adipocytes may have endothelial origins. In particular, lineage-tracing studies using the endothelial marker VEcadherin or the pre-adipocyte marker zinc finger protein 423 (ZFP423) also suggested that some brown and white adipocytes could originate from endothelial progenitors [30, 31]. Similarly, Shan et al identified aP2-expressing progenitors in SVF of both WAT and BAT [32]. In a more recent study, perilipin $^{+} /$adiponectin $^{+}$pre-adipocytes were found to emerge at embryonic day 16.5 in WAT and proliferated to form clusters interacting with growing adipose vasculature until birth while co-expressing stem cell markers such as cluster of differentiation (CD)24, CD29 and platelet-derived growth factor receptor $\alpha(\mathrm{PDGFR} \alpha)$ [33]. Some pre-adipocytes derived from PDGFR $\beta^{+}$mural cells. This study indicates that the endothelial origin of adipocytes is also embryonal. However, the view of an endothelial source of adipocytes is challenged by some lineage-tracing studies using other endothelial markers (i.e. cadherin-5 [Cdh5] and tyrosine kinase with immunoglobulinlike and EGF-like domain 2). Cdh5-expressing cells were traced by using $C d h 5$-Cre: $m T / m G$ and failed to show any Cdh5-derived adipocyte precursors within the SVF. Analysis performed with receptor tyrosine kinase Tie2-Cre produced similar negative results [34]. 
Specific origins for VAT and SAT One major gap in adipocyte biology is the incomplete understanding of the developmental origins of WAT. A recent study showed that VAT but not SAT arises from cells expressing the Wilms' tumour 1 gene (Wt1) late in mouse gestation [35]. Wt1 continues then to be expressed in VAT progenitors into adult life. The authors of this study also showed that VAT is lined by mesothelium and provided evidence that this structure is the source of adipocytes. Conversely, another study showed that the majority of the precursor and mature subcutaneous white adipocytes in adult $\mathrm{C} 57 \mathrm{Bl} / 6$ mice are labelled by $\operatorname{Prx} 1$-Cre whereas few to no brown adipocytes or visceral white adipocytes are labelled [36].

In between white and brown: origins of beige adipocytes Considering that beige adipocytes can arise from white APs by in vitro chronic exposure to peroxisome proliferator-activated receptor $\gamma(\operatorname{PPAR} \gamma)$ agonists, it is likely that they may share the same origin as most white adipocytes [37]. Recent evidence from adults suggests that beige adipocytes may form either by interconversion from white adipocytes or by proliferation and differentiation from specific precursors [2, 38]. Using mice in which UCP-1-expressing cells are constitutively or transiently labelled with fluorescent markers, beige adipocytes recruited after cold exposure were found to originate directly from white adipocytes. Although cold exposure has not yet been proven to induce SAT browning in humans [39], a recent study showed the presence of beige adipocytes in SAT of burns victims [40]. This is probably due to the chronically elevated circulating levels of noradrenaline (norepinephrine) found in their blood as part of a severe adrenergic stress response. Progressive recruitment of UCP $-1^{+}$multilocular adipocytes was observed in serial SAT biopsies obtained from these patients, possibly resulting from transdifferentiation of mature white cells.

Results supporting the 'specific precursor hypothesis' come from a study using the 'AdipoChaser model' indicating that cold-recruited beige cells are produced by clonal expansion of a precursor cell [2]. This is consistent with reports that beige adipocytes arise de novo in WAT in response to adrenergic stimulation as indicated by tracking beige adipogenesis using BrdU accumulation [41]. Similar lineage-tracking approaches identified self-renewing PDGFR $\alpha^{+}$precursors as a significant source of newly formed beige adipocytes; these PDGFR $\alpha^{+}$ progenitors are 'bi-potential', having the ability to produce both beige and white adipocytes when cultured in vitro [41]. In humans, native $\mathrm{CD} 45^{-} / \mathrm{CD} 34^{+} / \mathrm{CD} 31^{-}$cells were identified initially as human white APs [42, 43]. However, when additionally selected for the cell surface marker MSC antigen 1 they showed potential to become both white and beige in response to specific stimuli [44]. Beige adipocytes may also derive from dedicated beige adipocyte precursors, as indicated by a study characterising the in vitro adipogenic potential of immortalised WAT- and BAT-derived precursors showing that some of the
WAT precursors differentiated preferentially into beige adipocytes [19]. This suggests the existence of different types of adipocyte precursors in WAT, differing in their potential to produce beige adipocytes perhaps due to their lineage origins. For example, $\mathrm{PAX}^{-}$or $\mathrm{MYF}^{-}$adipocyte precursors isolated from WAT possess a higher potential to differentiate into brown-like cell genes compared with $\mathrm{PAX}^{+}$or $\mathrm{MYF}^{+}$precursors, respectively $[45,46]$.

In adult humans, inducible ectopic brown-like/beige depots have been observed in WAT surrounding the adrenal gland when the medulla develops a catecholamine-secreting tumour (i.e. phaeochromocytoma) [47]. Brown adipose stem cells were isolated from this peri-adrenal fat depot, which expresses brite/classical BAT markers and high levels of UCP-1, and their properties were compared with those of SAT precursors from the same patients. The findings demonstrated that BAT developing in peri-adrenal WAT derives from adult stem cells, unlike WAT precursors, suggesting an independent origin of the two fat depots.

SAT and BAT adipogenesis occurs during embryogenesis while VAT adipocytes preferentially differentiate postnatally. While BAT originates from paraxial mesoderm, WAT can have mesodermal and $\mathrm{NC}$ origins. White/brown adipogenesis can be reinitiated in adults in response to positive energy balance by differentiation of APs located within the vasculature. Whether the origin of a third class of adipocytes, 'beige/brite' adipocytes, is the result of white adipocyte trans-differentiation or differentiation of specific precursors is still a matter of debate

\section{Molecular and structural factors regulating adipogenesis}

Adipogenic cascade and molecular regulation White and brown adipogenesis are complex processes requiring coordination of multiple regulatory and signalling pathways. One family of proteins that contributes to the commitment of precursor cells (i.e. MSCs) to the white adipocyte programme is represented by the bone morphogenetic proteins (BMPS). While BMP4 induces differentiation of progenitor cells to white adipocytes in both humans [48] and mice [49], BMP2 does this in mice only [49]. Conversely, other factors such as fibroblast growth factor 2 (FGF-2) and activin A maintain MSCs in an undifferentiated proliferating state. White adipogenesis is also characterised by cell cycle arrest and the induction of mature white adipocyte machinery involving three key transcription factors: PPAR $\gamma 2$ [50], CCAT/enhancer-binding proteins (C/EBPs) and sterol regulatory element binding 
protein 1 (SREBP1). This has been extensively described in the literature [14] and is summarised in Fig. 1a.

As for white fat, brown adipocytes also need the induction of PPAR $\gamma 2$ and $\mathrm{C} / \mathrm{EBP} \alpha$ to reach their terminal differentiation. However, differentiation of brown adipocytes requires the presence of BMP7. Interestingly, BMP7 alone can stimulate the differentiation of brown pre-adipocytes and commit mesenchymal precursors to a brown adipocyte cell fate in mice [51]. BMP7 upregulates brown fat-specific markers, such as UCP1, PRDM16 and PGC- $1 \alpha / \beta$, inhibiting the expression of antiadipogenic molecules, such as PREF-1, WNT10a or nectin. A similar role has been described for BMP6 in both mice and humans [52]. Moreover, BMP7 and BMP8b are known to act as sensitisers of adrenergic signalling in mature brown adipocytes, leading to an increase in the sympathetic tone [53]. There are also other factors that direct the process toward a brown vs white adipocyte cell fate. For example, forkhead box C2 (FOXC2) modulates the expression and activity of adrenergic signalling molecules and $\mathrm{PGC} 1 \alpha$ coordinates expression of both mitochondrial and thermogenic genes [54].

Concerning beige adipocytes, regardless of whether they are derived from transdifferentiation of white adipocytes or from specific precursors $[41,55]$, their commitment towards a brown-like phenotype is promoted in vivo and in vitro by cold

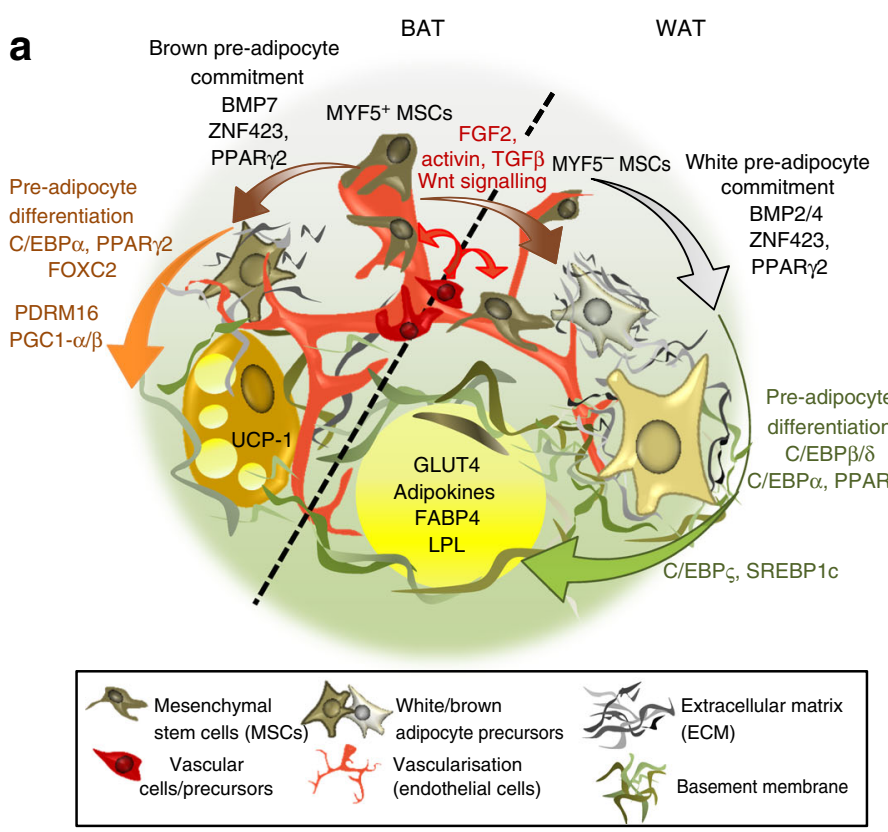

Fig. 1 BAT/WAT adipogenesis and associated tissue remodelling. (a) Adipogenesis consists of a two-step process involving, successively, mesenchymal precursors, committed pre-adipocytes, growth-arrested pre-adipocytes, mitotic clonal expansion, terminal differentiation and mature adipocytes. The first step of white adipocyte differentiation is the generation of pre-adipocytes from mesenchymal precursors (MSCs) MYF5 ${ }^{-}$ (grey arrow) or $\mathrm{MYF5}^{+}$(brown arrows), driven by BMP4. By promoting dissociation of the WISP2-ZNF423 complex, BMP4 allows nuclear entry of ZNF423 and PPAR $\gamma$ induction. Repression of ZNF521, which negatively regulates ZNF423 by repressing EBF1, also constitutes an early event in induction of white adipogenesis. The second step of adipogenesis is the differentiation of pre-adipocytes into mature adipocytes (green arrow), a process that involves the activation of transcription factors $\mathrm{C} / \mathrm{EBP} \beta$ and $\mathrm{C} / \mathrm{EBP} \delta$, first during mitotic clonal expansion of preadipocytes and subsequently induction of $\mathrm{C} / \mathrm{EBP} \alpha$ and $\mathrm{PPAR} \gamma 2$, which maintains the terminal differentiation of the adipocyte. Finally, SREBP1 is considered to be the third key transcription factor for adipogenesis, inducing expression of adipocyte-specific genes such as FABP4, adiponectin, GLUT4 (also known as SLC2A4), and $L P L$. C/EBP $\zeta$, a dominant inhibitor of $\mathrm{C} / \mathrm{EBP} \alpha$ and $\beta$, is induced in late adipocyte differentiation and has been proposed as an inhibitor of adipogenesis. Both canonical and non-canonical Wnt signalling pathways negatively regulate adipogenesis. $\beta$-Catenin mediates canonical Wnt signalling by activating cyclin D1, conversely with inhibition of PPAR $\gamma$ and $\mathrm{C} / \mathrm{EBP} \alpha$, causing a further decrease in adipogenesis. Similar to WAT, commitment of brown b

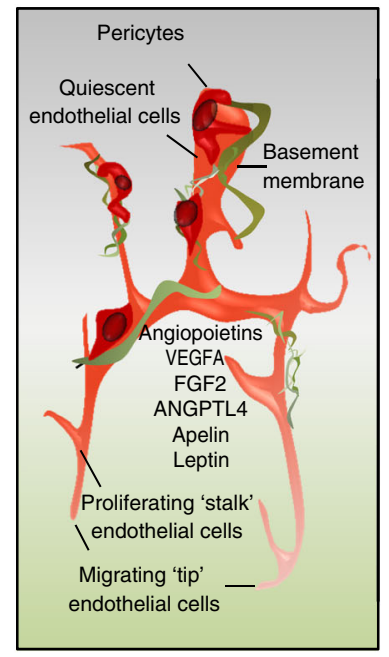

pre-adipocytes from $\mathrm{MYF}^{+}$MSCs (brown arrows) and differentiation into brown adipocytes (orange arrow) involves transcriptional control by $\mathrm{C} / \mathrm{EBPs}$ and PPAR $\gamma 2$ while some transcription factors, such as FOXC2, PGC1 $\alpha$ and PDRM16, are specific to brown cell fate leading to brownspecific thermogenic markers such as UCP-1. Recent evidence suggests that both brown and white adipocytes may derive from endothelial precursors (red arrows). (b) Angiogenesis is driven by angiogenic factors produced by adipocytes and vascular cells. VEGF-A is considered the main pro-angiogenic factor of AT. VEGF-A binds to VEGF receptors 1 and 2 to drive the migration of so-called 'tip cells', the ECs at the tip of a new capillary. Other growth factors such as ANGPTL4 and FGF-2 drive the migration and proliferation of stalk cells, the endothelial cells between the tip cells and the existing vessel that drive elongation. The new vessel is stabilised by the production of ECM components, forming the basement membrane, and the recruitment of pericytes. (c) Pre-adipocytes are surrounded by a fibrous ECM enriched in collagen I, collagen III and fibronectin replaced by the basement membrane, a specialised ECM surrounding mature adipocytes composed of collagen IV, collagen XVIII, entactin and laminin. ECM remodelling during adipogenesis involves degradation of pre-adipocyte ECM by proteases (MMPs, ADAMT and cathepsins). This liberates growth factors and matricellular proteins that are important for the synthesis of the new mature adipocyte basement membrane. ADAMT, a disintegrin and MMP with thrombospondin motifs; ANGPTL4, angiopoietin-like 4; EBF1, early B-cell factor 1; LPL, lipoprotein lipase 
stimulation and/or $\beta_{3}$ agonist or T3 similarly to brown cells. The exception is that beige adipogenesis does not require $\mathrm{C} / \mathrm{EBP} \alpha[56]$. Furthermore, a study performed in humans recently showed that, in addition to regulate white adipogenesis, BMP4 promotes the induction of a beige phenotype [57]. Other members of the BMP family have been reported to promote WAT browning in mice (i.e. BMP7 and BMP9) and humans (i.e. BMP7) $[58,59]$.

Some adipokines and adipocytokines such as adiponectin [60] are described to regulate BAT adipogenesis. Others such as IL-6 seem to be required for cold-induced UCP-1 expression in SAT [61]. Moreover, apelin promotes differentiation of brown adipocytes and browning of white fat by interacting with the APJ (apelin) receptor, which activates phosphoinositide 3-kinase (PI3K)/Akt and AMP-activated protein kinase signalling [62] while suppressing white adipogenesis [63].

Vascular and ECM remodelling in adipogenesis Appropriate vascularisation is required to ensure the development and growth of AT. Concomitantly with adipogenesis, angiogenic factors, such as FGF-2, vascular endothelial growth factor (VEGF) and human growth factor, are produced, mostly by APs, inducing a robust angiogenic response. AT growth requires an interaction between endothelial cells (ECs) and pre-adipocytes guiding cell migration via FGF- and VEGF-dependent pathways. The newly formed vessel is finally stabilised by the production of ECM and the recruitment of pericytes [4] (Fig. 1b). Overexpression of a dominant-negative form of PPAR $\gamma$ or the blockade of VEGF receptor 2 signalling by neutralising antibodies inhibits adipogenesis through impairment of both AT growth and angiogenesis. Conversely, pro-adipogenic factors such as PPAR $\gamma$ activation also promotes angiogenesis and EC motility and boosts expression levels of VEGF, VEGF-B, angiopoietin-like factor4 [64] and BMPs, which promote endothelial specification and subsequent venous differentiation during embryonic development [65].

During adipogenesis, formation and expansion of the lipid droplet requires a morphological change of the fibroblastic preadipocyte involving remodelling of both actin cytoskeleton [66] and ECM (Fig. 1c). This process requires enzymes such as metalloproteases (MMPs) that catalyse the degradation of collagen. Deficiency in MMP 9/10/12 does not affect adipogenesis, whereas single allele deficiency of MMP14/2 impairs it. Moreover, knockout mice for $M m p 3 / 11 / 19$, fed a high-fat diet (HFD) display marked hypertrophy of AT [67, 68]. Given that several growth/angiogenic factors such as VEGF are sequestered in the ECM, MMPs also seem to control preadipocyte differentiation and microvessel maturation by regulating degradation of the ECM.

Insulin also contributes to ECM turnover through regulation of the expression of enzymes involved in the posttransductional modification of some proteoglycans such as sulfatase-2. Moreover, insulin acts at a post-transcriptional level to increase production of mature type I collagen, collagen $\mathrm{V}$ fragment and C-terminal peptides of type I, II and III collagen. Insulin also increases the expression of prolyl-4-hydroxylase, involved in collagen stabilisation. Finally, COL6A2 and TSP1 have been identified as PPAR $\gamma$ target genes. Of note, the composition of ECM and its evolution during adipogenesis differs among fat depots. For example, expression levels of collagen IV and fibronectin are higher in VAT than in SAT, while in contrast, SAT is highly enriched in type I collagen [69] (Table 1).

Differences in adipocyte precursor pool and adipogenesis in AT depots Anatomical localisation influences adipogenesis in both humans and rodents with respect to proliferation and differentiation of SVF or APs. SVF cells isolated from human and rodent SAT display greater differentiation capacity compared with those from VAT (Table 1). This has been linked to higher gene expression of regulators of adipogenesis such as CEBP $\alpha$ or fatty acid binding protein 4 (FABP4), as well as greater response to PPAR $\gamma$ agonists, thiazolidinediones (TZDs). Consistently, TZD treatment enhanced fat storage preferentially in SAT [70]. Similarly to SVF cells, APs from SAT display higher expression levels of pro-adipogenic genes (PPAR $\gamma$ [PPARG], CEBPA, BMP2, BMP4 and DKK2) and differentiate better than those from VAT depot in response to classical adipogenic stimulus, the VAT requiring additional adipogenic factors such as BMP2/4 [71]. This might be partly explained by intrinsic differences of VAT APs exhibiting a 'mesenchymal stem cell'-like phenotype with higher expression of MSC markers (leukaemia inhibitory factor, connective tissue growth factor and matrix Gla protein) and adipogenic inhibitors such as GATA-binding protein 2 and TGFB2. Finally, clonogenic assays and in vivo BrdU studies in adult C57BL/6 mice showed that APs are eightfold more abundant in SAT than VAT [72, 73].

Adipogenesis and subsequent AT expansion require appropriate plasticity ensured by efficient remodelling of vasculature and ECM, both processes orchestrated by angiogenic/growth factors and ECM proteases. These processes are also influenced by the anatomical localisation and differentiation capacity of the precursor pools of the different AT depots

\section{Difference in AT plasticity between depots in obesity}

WAT expandability: hypertrophy vs hyperplasia in different fat depots Adipocyte hypertrophy is a hallmark of WAT enlargement in obesity and is typically associated with metabolic alterations and increased risk of developing type 2 diabetes, 
independently from total fat mass. In humans, adipocyte size is positively correlated with glucose intolerance and hyperinsulinaemia [74]. Moreover, inflammation and susceptibility to cell death are both increased in adipose depots with larger adipocytes [75]. Given the differences in adipocyte size/AP pool between SAT and VAT, it is not unexpected that plasticity is also differently affected, particularly when stressed by positive energy balance (Fig. 2a). Similarly, the percentage of small cells is higher in SAT and omental VAT in non-diabetic individuals than in diabetic obese individuals [76]. Recently, an HFD challenge time course experiment in mice revealed intra-depot differences in immune cell composition in relation to WAT expandability [77]. This study also indicated that gonadal VAT is the primary fat depot that expands during the initial phase of obesity, followed by the SAT and mesenteric VAT. Once the mice had reached a body weight of $40 \mathrm{~g}$, gonadal VAT stopped expanding further, in contrast to SAT and mesenteric VAT. Reaching this maximal expansion coincides with increased adipocyte death rate and formation of crown-like structures, inflammation and tissue dysfunction associated with insulin resistance and liver damage [78]. Similarly, another study has suggested that increased visceral mass predominantly results from adipocyte hypertrophy whereas hyperplasia is predominantly seen in SAT [73]. The resistance to differentiation observed in VAT APs and the fact the cells are more prone to cell death than those from SAT, may explain why hypertrophy preferentially occurs in VAT while SAT expands through hyperplasia as a result of the higher progenitor number and/or activity. Consistently, the number of small, early differentiated adipocytes, isolated from human SAT-derived SVF, correlates positively with subcutaneous adiposity (particularly in the femoral SAT), and negatively with VAT accumulation [79]. These data indicate that the abundance of adipocytes/APs in the SAT depots is an important determinant of SAT expandability and functionality. MSCs and pre-adipocytes with proliferative and adipogenic
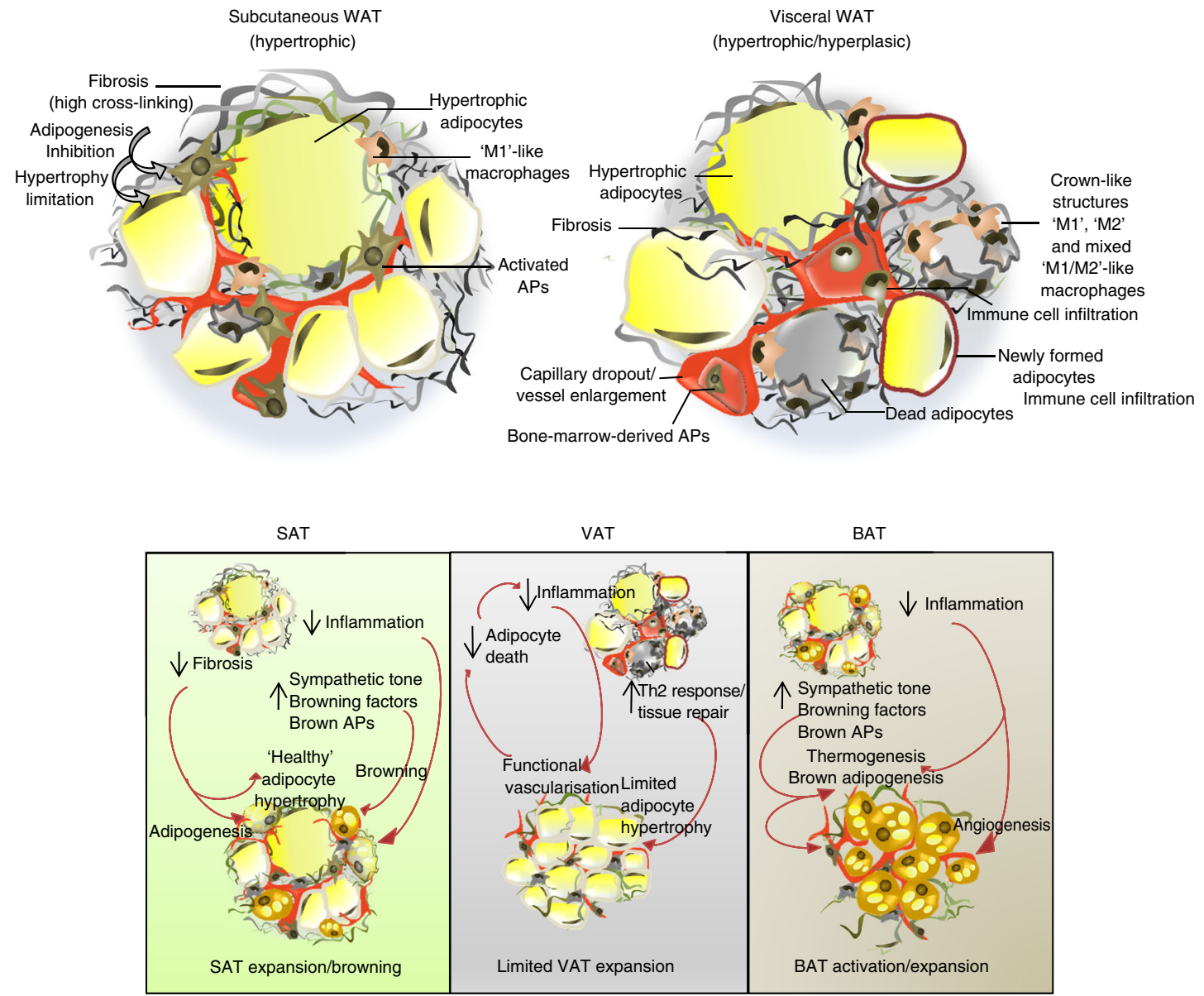

Fig. 2 SAT and VAT pathological remodelling in obesity and potential strategies. (a) WAT undergoes cellular and structural remodelling in obesity, characterised by the following: (1) adipocyte hypertrophy associated with production of inflammatory factors (VAT > SAT); (2) accumulation of immune cells such as macrophages organised around dead adipocytes (VAT > SAT); (3) decreased capillary density associated with EC dysfunction (i.e. activation, inflammation and senescence) (VAT > SAT); (4) activation of fibroblasts and APs (SAT > VAT) leading to fibrosis deposition and decreased tissue plasticity (SAT $>$ VAT). (b) Differential strategies between WAT and BAT depots to prevent obesity-related disorders, targeting tissue plasticity/remodelling and response to sympathetic tone, to promote healthy SAT expansion and browning, conversely with limited VAT expansion and lipotoxic action, and BAT activation and recruitment of APs 
capacity in adult WAT have recently been observed. For instance, while ${ }^{14} \mathrm{C}$ birth-dating experiments suggest that the number of adipocytes in SAT is relatively fixed in adulthood independently of BMI, there is now evidence for AP proliferation in human obesity [80]. Specifically, the number of adipocytes is higher in obese than in lean individuals, even after severe weight loss, indicating that increased adipocyte formation in obesity has lifelong effects on AT homeostasis and WAT mass. In mice, an HFD increases adipogenesis in SAT/ VAT of young animals but only in VAT of adults. Thus, a reduction in self-renewing division primarily in SAT might explain this phenomenon and suggests that metabolic disease ensues due to a primary failure of SAT plasticity [81]. However, it has been demonstrated recently that increased VAT mass in obese humans is primarily determined by adipocyte number rather than adipocyte hypertrophy [82]. Two independent studies using cell lineage tracing supported human data highlighting higher hyperplasic capacity in VAT compared with SAT during the development of obesity [2, 72]. In the murine model 'AdipoChaser', Wang et al showed that the main contributor to tissue expansion is hypertrophy during the first month of an HFD [2]. After prolonged exposure (i.e. $<1$ month) to HFD, a wave of adipogenesis is initiated preferentially in epididymal AT, whereas only negligible levels of adipogenesis occur in SAT depots. Similarly, Jeffery et al observed increased formation of adipocytes exclusively in VAT after 8 weeks of HFD, using the adiponectin-CreER;mT/mG mouse model to track newly formed adipocytes [72]. This was associated with increased proliferation of APs after the first week on HFD in VAT, but not in SAT, according to BrdU analysis. Timing differences between these studies could have contributed to these discrepancies considering that BrdU analysis of the study involving the AdipoChaser mouse on mice fed HFD was for an extended period of 12 weeks in comparison with the adiponectin-CreER;mT/mG mouse. Taken together, this data suggests that despite characteristically increased cellular proliferation in SAT, adipogenesis may be restricted to VAT at the onset of diet-induced obesity (Fig. 2a).

Origin of newly formed adipocytes in obesity In a study in mice, an 8 week HFD led to formation of new adipocytes in VAT, associated with activation and proliferation of $\mathrm{Lin}^{-} \mathrm{Sca}{ }^{+} \mathrm{CD}_{29}{ }^{+} \mathrm{CD} 34^{+}\left(\mathrm{CD} 24^{+}\right.$and $\left.\mathrm{CD} 24^{-}\right)$adipose progenitors through the $\mathrm{PI} 3 \mathrm{~K}-\mathrm{Akt} 2$ dependent pathway [72]. Interestingly, adipogenesis in response to the HFD did not require Akt2 suggesting a distinct molecular mechanism in obesogenic adipogenesis. This study also showed that APs begin to proliferate only 1 week after the start of the HFD suggesting that AP activation and proliferation in obesity occur before signals produced in response to hypertrophic adipocytes that have reached their maximal storage capacity, at least in the visceral depot. Moreover, the process of forming the mouse fat pad during development can be very different from the route by which new adipocytes are recruited in response to overnutrition.

A subset of bone-marrow-derived circulating progenitors can contribute to adipogenesis as suggested by the small population $(2-7 \%)$ of green fluorescent protein-expressing $\left(\mathrm{GFP}^{+}\right)$adipocytes resulting from transplantation of $\left(\mathrm{GFP}^{+}\right)$ bone-marrow-derived cells into mice [83]. This adipogenic process could be optimised (up to $8-25 \%$ ) in the presence of pro-adipogenic compounds or an HFD. Lineage analysis using LysMcreROSAflox/STOP mice in which LacZ expression is restricted to the myeloid lineage revealed the presence of labelled mature adipocytes, suggesting that bone-marrowderived adipocytes arise from myeloid progenitor cells [84]. A recent study of 65 individuals who underwent allogeneic bone marrow or peripheral blood stem cell transplantation showed, by taking advantage of genomic differences inherent to donor and recipient cells and performing both bulk and single-cell analyses, that $\sim 10 \%$ of bone marrow serves as a reservoir for AP in SAT, a contribution that increases up to 2.5 -fold in obese individuals [85]. However, the haematopoietic origin of adipocytes remains controversial since another lineagetracing study using a Vav1-Cre; R26R-mTmG knock-in model, where Vav1 is a proto-oncogene expressed in the haematopoietic and lymphoid systems, revealed that adipocyte precursors and mature adipocytes from the different WAT depots were negative for the fluorescence [34].

Hypertrophy preferentially occurs in VAT, while hyperplasia is more characteristic of SAT expansion due to higher progenitor number and/or activity in both human and rodents. However, in chronic states of obesity it is common that SAT adipogenesis is impaired while VAT still expands and contributes to metabolic alterations. Although still controversial, some studies have reported the contribution of haematopoietic precursors to newly formed adipocytes in obesity

\section{Pathological regulation of adipogenesis}

Impaired adipogenesis in obesity Failure of molecular effectors of lipid metabolism could at least partly explain dysregulated lipid storage and mobilisation. In obesity, expression of adipogenic genes (i.e. PPAR $\gamma 2, F A B P 4, F A S$ ) is decreased and this is further exacerbated in insulin resistance and type 2 diabetes [86]. Among the different studies highlighting the impairment of adipocyte differentiation in obesity one showed a reduced proportion of committed pre-adipocytes in SVF cells from SAT in obese individuals [87]. Interestingly, low SAT adipogenic rates are strongly associated with visceral obesity, omental adipocyte hypertrophy and metabolic 
dysregulation, independent of BMI [88]. Also of interest, SAT pre-adipocytes express high levels of mitogen-activated protein 4 kinase 4 (MAP4K4), a kinase induced by TNF $\alpha$ which is known to inhibit PPAR $\gamma$ and subsequent adipogenesis [89].

Adipogenesis and fibro-inflammation The effect inflammation has of inhibiting adipogenesis is relatively well characterised [90]. Chronic production of inflammatory factors in obesity results from infiltration and accumulation of immune cells. Among them, pro-inflammatory macrophages are recognised as main effectors, impairing adipogenesis in WAT [91]. The role of immune cells in mediating impairment of brite adipogenesis has also been reported [44]. In fact, inflammation also occurs in BAT from obese mice [92] and inflammatory factors produced by macrophages may inhibit brown adipogenesis [93].

The first wave of WAT accumulation of macrophages during early phases of obesity is essential for healthy tissue expansion and remodelling [94] and if these macrophages become inflammatory they disrupt ECM homeostasis, particularly when the inflammatory insult is sustained, leading to fibrosis deposition. Several studies have reported that the overexpression of ECM components observed in AT from obese individuals and genetically/nutritionally induced obese mice, is linked to metabolic dysfunction causing insulin resistance and liver damage $[5,95]$. In addition, fibrosis has a direct negative influence on AT tissue expansion in obesity through impairment of adipogenesis. Several pro-fibrotic factors have been shown to impair human pre-adipocyte differentiation. TGF- $\beta$ and related members such as activin $A$ are induced in obesity and negatively regulate adipogenesis.

PDGFR $\alpha^{+}$APs have also been suggested to promote WAT fibrosis [96]. The platelet-derived growth factor (PDGF) is an important profibrotic signal that binds the receptor tyrosine kinases PDGFR $\alpha$ and PDGFR $\beta$ [97]. A Nes-Cre strategy used to lineage trace pericytes and adventitial cells in WAT showed that despite little contribution of Nes-Cre/Tomato ${ }^{+}$ cells to WAT development in young mice, an HFD challenge significantly increases recruitment of PDGFR $\alpha^{+}$cells [96]. Moreover, in vitro these cells were able to differentiate into adipocytes. However, in vivo activation of PDGFR $\alpha$ signalling causes fibrosis [96]. The importance of PDGFR $\alpha$ signalling in obese WAT fibrosis remains to be tested, but it is tempting to speculate that PDGFR $\alpha$ activation could cause cell-autonomous fibrosis by perturbation of progenitor function.

Fibrosis limits AT expansion Fibrosis may also play a direct central role in the expandability of WAT by physically limiting adipocyte hypertrophy [95] (Fig. 2a). In obese mice, WAT fibrosis precedes development of other metabolic complications such as liver damage [78]. Other studies, essentially based on mouse models deficient for ECM or related proteins, support this hypothesis. For instance, increased type VI collagen deposits can be seen in SAT of obese individuals in association with insulin resistance $[98,99]$. Genetic ablation of collagens or remodelling enzymes profoundly affects adipocyte size and leads to metabolic consequences. Adipocyte hypertrophy in the absence of fibrotic deposits and inflammation develops in $o b / o b$ mice lacking collagen VI in WAT [100]. Despite their severe obesity, these mice are protected from metabolic complications. This suggests that in addition to limiting adipocyte hypertrophy, fibrosis might also impair adipocyte functionality $[95,101]$.

If accumulation of pericellular fibrosis in SAT is deleterious, there is some recent evidence showing that the fibrotic process in VAT of obese mice limits tissue expansion and related metabolic disorders [102]. In particular, this study revealed that HFD-fed mice with Irf5 deletion in macrophages display WAT remodelling with accumulation of noninflammatory macrophages (i.e. involved in ECM remodelling) in VAT leading to fibrosis deposition and limitation of tissue expansion. However, in this case these changes were associated with improved insulin sensitivity.

Given that the amount and activity of BAT also decreases with excess nutrients and fibro-inflammation, fibrotic BAT may exacerbate the development of obesity/complications. Recent evidence also suggests that inflammation and fibrosis negatively affect BAT functions highlighting the role of some molecular candidates involved in vasculature (e.g. VEGF) and ECM turnover, such as TGF- $\beta$, endotrophin and microfibrilassociated glycoprotein-1 [103-105].

Adipogenesis is impaired in obesity as a result of a chronic fibro-inflammatory environment where the increase of cytokines and ECM proteins disrupts AP differentiation and promotes activation of fibrotic signalling. In addition, fibrosis mechanically limits tissue plasticity, contributing to metabolic alterations

\section{Concluding remarks and future perspectives}

Bearing in mind interspecies differences, we suggest that the pathological effects of obesity and related metabolic complications maybe ameliorated by the following: (1) improving the nutrient storage capacity of SAT and simultaneously limiting the storage capacity of VAT by targeting the AT fibroinflammatory environment; (2) increasing the recruitment capability of WAT precursors and, as a consequence, WAT's expandability potential and/or (3) increasing BAT mass/activity and SAT browning/beige adipocyte recruitment (Fig. 2b). These strategies will allow the maximisation of the energydissipating potential of thermogenic brown and beige adipocytes. In our opinion, this achievement will only be possible 
with a better understanding of the developmental origins, as well as molecular and physiological nature and plasticity, of adipocytes forming different AT depots in humans during the onset of obesity. This will provide a rationale for translational strategies to improve WAT expandability and brown/beige cell recruitment and activation, moving from rodent models to a clinical context and later on success.

Acknowledgements We apologise to those whose work was not directly cited because of space constraints. We thank K. Ketteridge-Lowe (Wellcome Trust-MRC Institute of Metabolic Science, Cambridge, UK) for editorial assistance.

Funding The authors are supported by FP7 BetaBAT, BBSRC, BHF and MRC programme grants and the Wellcome Trust. VP is supported by a WHRI-ACADEMY postdoctoral fellowship.

Duality of interest The author declares that there is no duality of interest associated with this manuscript.

Contribution statement All authors provided substantial contributions to the conception of the manuscript, drafted and revised the manuscript critically for intellectual content and approved the final version of the manuscript.

Open Access This article is distributed under the terms of the Creative Commons Attribution 4.0 International License (http:// creativecommons.org/licenses/by/4.0/), which permits unrestricted use, distribution, and reproduction in any medium, provided you give appropriate credit to the original author(s) and the source, provide a link to the Creative Commons license, and indicate if changes were made.

\section{References}

1. Wronska A, Kmiec Z (2012) Structural and biochemical characteristics of various white adipose tissue depots. Acta Physiol (Oxf) 205:194-208

2. Wang QA, Tao C, Gupta RK, Scherer PE (2013) Tracking adipogenesis during white adipose tissue development, expansion and regeneration. Nat Med 19:1338-1344

3. Lolmède K, Duffaut C, Zakaroff-Girard A, Bouloumié A (2011) Immune cells in adipose tissue: key players in metabolic disorders. Diabetes Metab 37:283-290

4. Cao Y (2013) Angiogenesis and vascular functions in modulation of obesity, adipose metabolism, and insulin sensitivity. Cell Metab 18:478-489

5. Sun K, Tordjman J, Clément K, Scherer PE (2013) Fibrosis and adipose tissue dysfunction. Cell Metab 18:470-477

6. Jensen MD (2008) Role of body fat distribution and the metabolic complications of obesity. J Clin Endocrinol Metab 93:S57-S63

7. Arner E, Westermark PO, Spalding KL et al (2010) Adipocyte turnover: relevance to human adipose tissue morphology. Diabetes 59:105-109

8. Kim J-Y, van de Wall E, Laplante M et al (2007) Obesityassociated improvements in metabolic profile through expansion of adipose tissue. J Clin Invest 117:2621-2637

9. Foster MT, Shi H, Seeley RJ, Woods SC (2011) Removal of intraabdominal visceral adipose tissue improves glucose tolerance in rats: role of hepatic triglyceride storage. Physiol Behav 104:845854

10. Hocking SL, Stewart RL, Brandon AE et al (2015) Subcutaneous fat transplantation alleviates diet-induced glucose intolerance and inflammation in mice. Diabetologia 58:1587-1600

11. Cypess AM, Lehman S, Williams G et al (2009) Identification and importance of brown adipose tissue in adult humans. N Engl J Med 360:1509-1517

12. van Marken Lichtenbelt WD, Vanhommerig JW, Smulders NM et al (2009) Cold-activated brown adipose tissue in healthy men. N Engl J Med 360:1500-1508

13. Virtanen KA, Lidell ME, Orava J et al (2009) Functional brown adipose tissue in healthy adults. N Engl J Med 360:1518-1525

14. Peirce V, Carobbio S, Vidal-Puig A (2014) The different shades of fat. Nature 510:76-83

15. Ibrahim MM (2010) Subcutaneous and visceral adipose tissue: structural and functional differences. Obes Rev 11:11-18

16. Fedorenko A, Lishko PV, Kirichok Y (2012) Mechanism of fattyacid-dependent UCP1 uncoupling in brown fat mitochondria. Cell 151:400-413

17. Orava J, Nuutila P, Lidell ME et al (2011) Different metabolic responses of human brown adipose tissue to activation by cold and insulin. Cell Metab 14:272-279

18. Sbarbati A, Accorsi D, Benati D et al (2010) Subcutaneous adipose tissue classification. Eur J Histochem 54:e48

19. Wu J, Boström P, Sparks LM et al (2012) Beige adipocytes are a distinct type of thermogenic fat cell in mouse and human. Cell 150:366-376

20. Poissonnet CM, Burdi AR, Garn SM (1984) The chronology of adipose tissue appearance and distribution in the human fetus. Early Hum Dev 10:1-11

21. Crandall DL, Hausman GJ, Kral JG (1997) A review of the microcirculation of adipose tissue: anatomic, metabolic, and angiogenic perspectives. Microcirculation 4:211-232

22. Contreras GA, Lee Y-H, Mottillo EP, Granneman JG (2014) Inducible brown adipocytes in subcutaneous inguinal white fat: the role of continuous sympathetic stimulation. Am J Physiol Endocrinol Metab 307:E793-E799

23. Atit R, Sgaier SK, Mohamed OA et al (2006) Beta-catenin activation is necessary and sufficient to specify the dorsal dermal fate in the mouse. Dev Biol 296:164-176

24. Lepper C, Fan C-M (2010) Inducible lineage tracing of Pax7descendant cells reveals embryonic origin of adult satellite cells. Genesis 48:424-436

25. Sanchez-Gurmaches J, Guertin DA (2014) Adipocyte lineages: tracing back the origins of fat. Biochim Biophys Acta 1842: 340-351

26. Sanchez-Gurmaches J, Hung C-M, Sparks CA et al (2012) PTEN loss in the Myf5 lineage redistributes body fat and reveals subsets of white adipocytes that arise from Myf5 precursors. Cell Metab $16: 348-362$

27. Billon N, Iannarelli P, Monteiro MC et al (2007) The generation of adipocytes by the neural crest. Development 134:2283-2292

28. Takashima Y, Era T, Nakao K et al (2007) Neuroepithelial cells supply an initial transient wave of MSC differentiation. Cell 129: 1377-1388

29. Rodeheffer MS, Birsoy K, Friedman JM (2008) Identification of white adipocyte progenitor cells in vivo. Cell 135:240-249

30. Gupta RK, Mepani RJ, Kleiner S et al (2012) Zfp423 expression identifies committed preadipocytes and localizes to adipose endothelial and perivascular cells. Cell Metab 15:230-239

31. Tran K-V, Gealekman O, Frontini A et al (2012) The vascular endothelium of the adipose tissue gives rise to both white and brown fat cells. Cell Metab 15:222-229 
32. Shan T, Liu W, Kuang S (2013) Fatty acid binding protein 4 expression marks a population of adipocyte progenitors in white and brown adipose tissues. FASEB J 27:277-287

33. Hong KY, Bae H, Park I et al (2015) Perilipin+ embryonic preadipocytes actively proliferate along growing vasculatures for adipose expansion. Development 142:2623-2632

34. Berry R, Rodeheffer MS (2013) Characterization of the adipocyte cellular lineage in vivo. Nat Cell Biol 15:302-308

35. Chau Y-Y, Bandiera R, Serrels A et al (2014) Visceral and subcutaneous fat have different origins and evidence supports a mesothelial source. Nat Cell Biol 16:367-375

36. Sanchez-Gurmaches J, Hsiao W-Y, Guertin DA (2015) Highly selective in vivo labeling of subcutaneous white adipocyte precursors with Prx1-Cre. Stem Cell Rep 4:541-550

37. Petrovic N, Walden TB, Shabalina IG et al (2010) Chronic peroxisome proliferator-activated receptor $\gamma(\operatorname{PPAR} \gamma)$ activation of epididymally derived white adipocyte cultures reveals a population of thermogenically competent, UCP1-containing adipocytes molecularly distinct from classic brown adipocytes. J Biol Chem 285:7153-7164

38. Lee Y-H, Petkova AP, Konkar AA, Granneman JG (2015) Cellular origins of cold-induced brown adipocytes in adult mice. FASEB J 29:286-299

39. van der Lans AAJJ, Hoeks J, Brans B et al (2013) Cold acclimation recruits human brown fat and increases nonshivering thermogenesis. J Clin Invest 123:3395-3403

40. Sidossis LS, Porter C, Saraf MK et al (2015) Browning of subcutaneous white adipose tissue in humans after severe adrenergic stress. Cell Metab 22:219-227

41. Lee Y-H, Petkova AP, Mottillo EP, Granneman JG (2012) In vivo identification of bipotential adipocyte progenitors recruited by $\beta 3$ adrenoceptor activation and high-fat feeding. Cell Metab 15:480-491

42. Sengenès C, Lolmède K, Zakaroff-Girard A et al (2005) Preadipocytes in the human subcutaneous adipose tissue display distinct features from the adult mesenchymal and hematopoietic stem cells. J Cell Physiol 205:114-122

43. Elabd C, Chiellini C, Carmona M et al (2009) Human multipotent adipose-derived stem cells differentiate into functional brown adipocytes. Stem Cells 27:2753-2760

44. Estève D, Boulet N, Volat F et al (2015) Human white and brite adipogenesis is supported by MSCA1 and is impaired by immune cells. Stem Cells 33:1277-1291

45. Liu W, Shan T, Yang X et al (2013) A heterogeneous lineage origin underlies the phenotypic and molecular differences of white and beige adipocytes. J Cell Sci 126:3527-3532

46. Sanchez-Gurmaches J, Guertin DA (2014) Adipocytes arise from multiple lineages that are heterogeneously and dynamically distributed. Nat Commun 5:4099

47. Lenders JWM, Eisenhofer G, Mannelli M, Pacak K (2005) Phaeochromocytoma. Lancet 366:665-675

48. Suenaga M, Kurosawa N, Asano H et al (2013) Bmp4 expressed in preadipocytes is required for the onset of adipocyte differentiation. Cytokine 64:138-145

49. Huang H, Song T-J, Li X et al (2009) BMP signaling pathway is required for commitment of $\mathrm{C} 3 \mathrm{H} 10 \mathrm{~T} 1 / 2$ pluripotent stem cells to the adipocyte lineage. Proc Natl Acad Sci U S A 106:1267012675

50. Shao X, Wang M, Wei X et al (2015) Peroxisome proliferator-activated receptor- $\gamma$ : master regulator of adipogenesis and obesity. Curr Stem Cell Res Ther 11:282-289

51. Tseng Y-H, Kokkotou E, Schulz TJ et al (2008) New role of bone morphogenetic protein 7 in brown adipogenesis and energy expenditure. Nature 454:1000-1004

52. Sharma A, Huard C, Vernochet C et al (2014) Brown fat determination and development from muscle precursor cells by novel action of bone morphogenetic protein 6. PLoS One 9:e92608
53. Whittle AJ, Carobbio S, Martins L et al (2012) BMP8B increases brown adipose tissue thermogenesis through both central and peripheral actions. Cell 149:871-885

54. Lidell ME, Seifert EL, Westergren R et al (2011) The adipocyteexpressed forkhead transcription factor Foxc2 regulates metabolism through altered mitochondrial function. Diabetes 60:427-435

55. Rosenwald M, Perdikari A, Rülicke T, Wolfrum C (2013) Bidirectional interconversion of brite and white adipocytes. Nat Cell Biol 15:659-667

56. Wang QA, Tao C, Jiang L et al (2015) Distinct regulatory mechanisms governing embryonic versus adult adipocyte maturation. Nat Cell Biol 17:1099-1111

57. Gustafson B, Hammarstedt A, Hedjazifar S et al (2015) BMP4 and BMP antagonists regulate human white and beige adipogenesis. Diabetes 64:1670-1681

58. Schulz TJ, Huang TL, Tran TT et al (2011) Identification of inducible brown adipocyte progenitors residing in skeletal muscle and white fat. Proc Natl Acad Sci U S A 108:143-148

59. Kuo MM-C, Kim S, Tseng C-Y et al (2014) BMP-9 as a potent brown adipogenic inducer with anti-obesity capacity. Biomaterials 35:3172-3179

60. Masaki T, Chiba S, Yasuda T et al (2003) Peripheral, but not central, administration of adiponectin reduces visceral adiposity and upregulates the expression of uncoupling protein in agouti yellow (Ay/a) obese mice. Diabetes 52:2266-2273

61. Knudsen JG, Murholm M, Carey AL et al (2014) Role of IL-6 in exercise training- and cold-induced UCP1 expression in subcutaneous white adipose tissue. PLoS One 9:e84910

62. Than A, He HL, Chua SH et al (2015) Apelin enhances brown adipogenesis and browning of white adipocytes. J Biol Chem 290: 14679-14691

63. Than A, Cheng Y, Foh L-C et al (2012) Apelin inhibits adipogenesis and lipolysis through distinct molecular pathways. Mol Cell Endocrinol 362:227-241

64. Gealekman O, Burkart A, Chouinard M et al (2008) Enhanced angiogenesis in obesity and in response to PPARgamma activators through adipocyte VEGF and ANGPTL4 production. Am J Physiol Endocrinol Metab 295:E1056-E1064

65. Dyer LA, Pi X, Patterson C (2014) The role of BMPs in endothelial cell function and dysfunction. Trends Endocrinol Metab 25: 472-480

66. McBeath R, Pirone DM, Nelson CM et al (2004) Cell shape, cytoskeletal tension, and RhoA regulate stem cell lineage commitment. Dev Cell 6:483-495

67. Bauters D, Van Hul M, Lijnen HR (2013) Macrophage elastase (MMP-12) in expanding murine adipose tissue. Biochim Biophys Acta 1830:2954-2959

68. Mariman ECM, Wang P (2010) Adipocyte extracellular matrix composition, dynamics and role in obesity. Cell Mol Life Sci 67: 1277-1292

69. Mori S, Kiuchi S, Ouchi A et al (2014) Characteristic expression of extracellular matrix in subcutaneous adipose tissue development and adipogenesis; comparison with visceral adipose tissue. Int J Biol Sci 10:825-833

70. Smith SR, De Jonge L, Volaufova J et al (2005) Effect of pioglitazone on body composition and energy expenditure: a randomized controlled trial. Metab Clin Exp 54:24-32

71. Macotela Y, Emanuelli B, Mori MA et al (2012) Intrinsic differences in adipocyte precursor cells from different white fat depots. Diabetes 61:1691-1699

72. Jeffery E, Church CD, Holtrup B et al (2015) Rapid depot-specific activation of adipocyte precursor cells at the onset of obesity. Nat Cell Biol 17:376-385

73. Joe AWB, Yi L, Even Y et al (2009) Depot-specific differences in adipogenic progenitor abundance and proliferative response to high-fat diet. Stem Cells 27:2563-2570 
74. Weyer C, Foley JE, Bogardus C et al (2000) Enlarged subcutaneous abdominal adipocyte size, but not obesity itself, predicts type II diabetes independent of insulin resistance. Diabetologia 43: 1498-1506

75. Skurk T, Alberti-Huber C, Herder C, Hauner H (2007) Relationship between adipocyte size and adipokine expression and secretion. J Clin Endocrinol Metab 92:1023-1033

76. Fang L, Guo F, Zhou L et al (2015) The cell size and distribution of adipocytes from subcutaneous and visceral fat is associated with type 2 diabetes mellitus in humans. Adipocyte 4:273-279

77. van Beek L, van Klinken JB, Pronk ACM et al (2015) The limited storage capacity of gonadal adipose tissue directs the development of metabolic disorders in male $\mathrm{C} 57 \mathrm{Bl} / 6 \mathrm{~J}$ mice. Diabetologia 58: 1601-1609

78. Strissel KJ, Stancheva Z, Miyoshi H et al (2007) Adipocyte death, adipose tissue remodeling, and obesity complications. Diabetes 56:2910-2918

79. Tchoukalova YD, Koutsari C, Votruba SB et al (2010) Sex- and depot-dependent differences in adipogenesis in normal-weight humans. Obesity (Silver Spring) 18:1875-1880

80. Spalding KL, Arner E, Westermark PO et al (2008) Dynamics of fat cell turnover in humans. Nature 453:783-787

81. Kim SM, Lun M, Wang M et al (2014) Loss of white adipose hyperplastic potential is associated with enhanced susceptibility to insulin resistance. Cell Metab 20:1049-1058

82. Arner P, Andersson DP, Thörne A et al (2013) Variations in the size of the major omentum are primarily determined by fat cell number. J Clin Endocrinol Metab 98:E897-901

83. Crossno JT, Majka SM, Grazia T et al (2006) Rosiglitazone promotes development of a novel adipocyte population from bone marrow-derived circulating progenitor cells. J Clin Invest 116: 3220-3228

84. Majka SM, Fox KE, Psilas JC et al (2010) De novo generation of white adipocytes from the myeloid lineage via mesenchymal intermediates is age, adipose depot, and gender specific. Proc Natl Acad Sci U S A 107:14781-14786

85. Rydén M, Uzunel M, Hård JL et al (2015) Transplanted bone marrow-derived cells contribute to human adipogenesis. Cell Metab 22:408-417

86. Dubois SG, Heilbronn LK, Smith SR et al (2006) Decreased expression of adipogenic genes in obese subjects with type 2 diabetes. Obesity (Silver Spring) 14:1543-1552

87. Tchoukalova Y, Koutsari C, Jensen M (2007) Committed subcutaneous preadipocytes are reduced in human obesity. Diabetologia 50:151-157

88. Lessard J, Laforest S, Pelletier M et al (2014) Low abdominal subcutaneous preadipocyte adipogenesis is associated with visceral obesity, visceral adipocyte hypertrophy, and a dysmetabolic state. Adipocyte 3:197-205

89. Tesz GJ, Guilherme A, Guntur KVP et al (2007) Tumor necrosis factor $\alpha(\mathrm{TNF} \alpha)$ stimulates Map4k4 expression through TNF $\alpha$ receptor 1 signaling to $\mathrm{c}-\mathrm{Jun}$ and activating transcription factor 2. J Biol Chem 282:19302-19312

90. Gustafson B, Hedjazifar S, Gogg S et al (2015) Insulin resistance and impaired adipogenesis. Trends Endocrinol Metab 26:193-200

91. Lacasa D, Taleb S, Keophiphath M et al (2007) Macrophagesecreted factors impair human adipogenesis: involvement of proinflammatory state in preadipocytes. Endocrinology 148:868-877

92. Roberts-Toler C, O’Neill BT, Cypess AM (2015) Diet-induced obesity causes insulin resistance in mouse brown adipose tissue. Obesity (Silver Spring) 23:1765-1770

93. Sakamoto T, Takahashi N, Sawaragi Y et al (2013) Inflammation induced by RAW macrophages suppresses UCP1 mRNA induction via ERK activation in 10T1/2 adipocytes. Am J Physiol Cell Physiol 304:C729-C738
94. Wernstedt Asterholm I, Tao C, Morley TS et al (2014) Adipocyte inflammation is essential for healthy adipose tissue expansion and remodeling. Cell Metab 20:103-118

95. Abdennour M, Reggio S, Le Naour G et al (2014) Association of adipose tissue and liver fibrosis with tissue stiffness in morbid obesity: links with diabetes and BMI loss after gastric bypass. J Clin Endocrinol Metab 99:898-907

96. Iwayama T, Steele C, Yao L et al (2015) PDGFR $\alpha$ signaling drives adipose tissue fibrosis by targeting progenitor cell plasticity. Genes Dev 29:1106-1119

97. Bonner JC (2004) Regulation of PDGF and its receptors in fibrotic diseases. Cytokine Growth Factor Rev 15:255-273

98. Pasarica M, Gowronska-Kozak B, Burk D et al (2009) Adipose tissue collagen VI in obesity. J Clin Endocrinol Metab 94:51555162

99. Spencer M, Yao-Borengasser A, Unal R et al (2010) Adipose tissue macrophages in insulin-resistant subjects are associated with collagen VI and fibrosis and demonstrate alternative activation. Am J Physiol Endocrinol Metab 299:E1016-E1027

100. Khan T, Muise ES, lyengar P et al (2009) Metabolic dysregulation and adipose tissue fibrosis: role of collagen VI. Mol Cell Biol 29: 1575-1591

101. Pellegrinelli V, Heuvingh J, du Roure O et al (2014) Human adipocyte function is impacted by mechanical cues. J Pathol 233: 183-195

102. Dalmas E, Toubal A, Alzaid F et al (2015) Irf5 deficiency in macrophages promotes beneficial adipose tissue expansion and insulin sensitivity during obesity. Nat Med 21:610-618

103. Craft CS, Pietka TA, Schappe T et al (2014) The extracellular matrix protein MAGP1 supports thermogenesis and protects against obesity and diabetes through regulation of TGF- $\beta$. Diabetes 63:1920-1932

104. Sun K, Park J, Gupta OT et al (2014) Endotrophin triggers adipose tissue fibrosis and metabolic dysfunction. Nat Commun 5:3485

105. Bagchi M, Kim LA, Boucher J et al (2013) Vascular endothelial growth factor is important for brown adipose tissue development and maintenance. FASEB J 27:3257-3271

106. Prunet-Marcassus B, Cousin B, Caton D et al (2006) From heterogeneity to plasticity in adipose tissues: site-specific differences. Exp Cell Res 312:727-736

107. Hames KC, Koutsari C, Santosa S et al (2015) Adipose tissue fatty acid storage factors: effects of depot, sex and fat cell size. Int J Obes (Lond) 39:884-887

108. Meyer LK, Ciaraldi TP, Henry RR et al (2013) Adipose tissue depot and cell size dependency of adiponectin synthesis and secretion in human obesity. Adipocyte 2:217-226

109. Zhang Y, Zitsman JL, Hou J et al (2014) Fat cell size and adipokine expression in relation to gender, depot, and metabolic risk factors in morbidly obese adolescents. Obesity (Silver Spring) 22:691-697

110. Villaret A, Galitzky J, Decaunes P et al (2010) Adipose tissue endothelial cells from obese human subjects: differences among depots in angiogenic, metabolic, and inflammatory gene expression and cellular senescence. Diabetes 59:2755-2763

111. Cinti S (2009) Transdifferentiation properties of adipocytes in the adipose organ. Am J Physiol Endocrinol Metab 297:E977-E986

112. Gealekman O, Guseva N, Hartigan C et al (2011) Depot-specific differences and insufficient subcutaneous adipose tissue angiogenesis in human obesity. Circulation 123:186-194

113. Xue Y, Lim S, Bråkenhielm E, Cao Y (2010) Adipose angiogenesis: quantitative methods to study microvessel growth, regression and remodeling in vivo. Nat Protoc 5:912-920

114. Rosell M, Kaforou M, Frontini A et al (2014) Brown and white adipose tissues. Intrinsic differences in gene expression and response to cold exposure in mice. Am J Physiol Endocrinol Metab 306:E945-E964 
115. Murano I, Barbatelli G, Giordano A, Cinti S (2009) Noradrenergic parenchymal nerve fiber branching after cold acclimatisation correlates with brown adipocyte density in mouse adipose organ. J Anat 214:171-178

116. Kranendonk MEG, van Herwaarden JA, Stupkova T et al (2015) Inflammatory characteristics of distinct abdominal adipose tissue depots relate differently to metabolic risk factors for cardiovascular disease: distinct fat depots and vascular risk factors. Atherosclerosis 239:419-427

117. Cancello R, Tordjman J, Poitou C et al (2006) Increased infiltration of macrophages in omental adipose tissue is associated with marked hepatic lesions in morbid human obesity. Diabetes 55:1554-1561
118. Fitzgibbons TP, Kogan S, Aouadi M et al (2011) Similarity of mouse perivascular and brown adipose tissues and their resistance to diet-induced inflammation. Am J Physiol Heart Circ Physiol 301:H1425-H1437

119. McCulloch LJ, Rawling TJ, Sjöholm K et al (2015) COL6A3 is regulated by leptin in human adipose tissue and reduced in obesity. Endocrinology 156:134-146

120. Roca-Rivada A, Belen Bravo S, Pérez-Sotelo D et al (2015) CILAIR-based secretome analysis of obese visceral and subcutaneous adipose tissues reveals distinctive ECM Remodeling and Inflammation Mediators. Sci Rep 5:12214 